\title{
La vía de Pola de Allande a Grandas de Salime (vía romana del Puerto del Palo)
}

\author{
Narciso Santos Yanguas *
}

\begin{abstract}
RESUMEN ABSTRACT
La red viaria romana de los primeros siglos de nuestra era constituye, en el marco geográfico del Suroccidente de Asturias, el hilo conductor del proceso de asimilación de la organización romana.

En torno a esta vía del concejo de Allande girará el desarrollo de los núcleos de habitat (recintos castreños) y el aprovechamiento de los recursos auriferos.

De esta manera la base económica (actividades mineras) se convierte en el factor vertebrador que hace comprensible el sentido de la romanización de esta región asturiana.

The Roman road system of the first centuries of our age explains in itself, and within the South-Western area of Asturias, the process of assimilation of Roman organization. The development of settlements (castra) and exploitation of golden deposits will be carried our along this road in the Concejo of Allande.

Thus, the economic basis (mining exploitations) becomes the main clue to understand the process of romanization of this Asturian region.
\end{abstract}

La minería romana del oro constituye sin duda la base principal que nos ayuda a comprender el proceso de romanización (entendiendo por tal la aceptación y/o el rechazo de las formas de vida romanas por parte de los indígenas habitantes de los castros ${ }^{1}$ ) que se iba a operar en el transcurso

\footnotetext{
* Universidad de Oviedo.

En realidad en la interacción de las formas de vida romanas y las propias de las comunidades de la Península Ibérica este proceso dinámico únicamente surtiría efecto a partir del momento en que
} 
de los dos primeros siglos de nuestra era (en especial entre los años 50 y 180 aproximadamente) en el marco del territorio correspondiente al Suroccidente de Asturias; además, no debemos olvidar que va a ser a lo largo de dichas décadas cuando se implanten, con mayor o menor intensidad, los parámetros propios de la organización romana en dicho suelo ${ }^{2}$.

Ahora bien, el análisis que pretendemos llevar a cabo en las páginas siguientes no va a quedar reducido a una mera catalogación y clasificación, lo más completas y exhaustivas posibles en cada caso ${ }^{3}$, de los centros de habitat existentes en el marco del suelo perteneciente a las poblaciones septentrionales castreñas (de forma especial en el concejo de Allande).

Simultáneamente se convertirán en objeto de nuestro estudio las características que nos ofrece la presencia (así como el aprovechamiento y explotación) de los centros de recursos mineros ${ }^{4}$ enclavados en el suelo próximo a los núcleos de población indígena en el transcurso de los años correspondientes a la etapa del Alto Imperio romano ${ }^{5}$.

De la interconexión existente entre ambos elementos se desprende fácilmente el hecho de que durante esta época histórica (a grandes rasgos los dos primeros siglos de nuestra era) tanto los recintos de habitat fortificados como los centros de explotación minera del oro se relacionarían necesariamente con una red viaria de características especiales; dicho entramado de comunicaciones acabaría por convertirse desde una época muy temprana en el vehículo de transmisión de ese proceso de asimilación y/o rechazo de las formas culturales romanas por parte de las poblaciones indigenas.

$Y$ todo ello teniendo presente siempre que, entre los factores que influirian de manera directa y decisiva en la evolución histórica del territorio suroccidental de Asturias en época romana, favoreciendo de esta manera el proceso de romanización o aculturación romana de la región, cabe destacar como más significativos los siguientes:

la población indigena estuviese dispuesta a aceptar las estructuras de organización romanas (en un principio se mostraría algo reticente, pero con el paso del tiempo aceptaría de buen grado su inclusión en el marco de una cultura más evolucionada).

Estas cuestiones fueron tratadas ya hace años, por ejemplo, por M.D.N.ESTEFANÍA ÁLVAREZ, "Aspectos económicos de la penetración y colonización romana de Asturias", Emerita 31 (1963) 43ss.

3 Con estos objetivos existen ya las Cartas arqueológicas correspondientes a cada una de las circunscripciones administrativas actuales (concejos) de este contexto territorial correspondiente al Suroccidente del Principado de Asturias.

Básicamente auriferos, y en ocasiones aisladas de otros metales, como el hierro por ejemplo (en casi todos los casos asociados a la explotación aurifera).

Sin olvidar en ningun momento los caminos que ponian en contacto los recintos poblacionales con los enclaves de aprovechamiento de los recursos económicos. 
1. la presencia del ejército romano y la participación de los indígenas en el marco de dichas unidades militares ${ }^{6}$;

2. el trazado de un entramado viario de comunicaciones suficientemente extenso ${ }^{7}$;

3. el poblamiento de la zona en el transcurso de los siglos correspondientes a la etapa castreña romana ${ }^{8} ; y$

4. finalmente, el aprovechamiento intensivo de los recursos económicos vinculados a la minería (centros de explotación del oro).

Teniendo en cuenta dicho planteamiento hemos de contextualizar el camino de comunicación antiguo que nos disponemos a analizar, conocido comúnmente por parte de los investigadores como «vía romana del Puerto del Palo»; su existencia parece consolidarse precisamente en época romana, teniendo que hacer remontar, sin embargo, sus orígenes a la fase histórica anterior de acuerdo con los testimonios que la cultura dolménica nos ha dejado en sus aledaños: en este sentido destaca de manera especial la abundante localización de túmulos, de los que se ha descubierto un buen número de ellos en la Sierra de Fonfaraón ${ }^{\text {. }}$

Constituye sin duda, a pesar de no disponer de vestigios y restos antiguos (recintos de población castreña y centros de explotación del oro) tan abundantes y significativos como, por ejemplo, los correspondientes a la región del Valledor ${ }^{10} \mathrm{o}$ a los descubiertos en la cuenca del Arganza en el

Como enfoque general remitimos a J.M. ROLDAN, Hispania y el ejército romano. Contribución a la historia social de la España antigua, Salamanca 1974. Para el caso concreto de los astures se puede consultar, entre otros. N. Santos. El ejército romano y la romanización de los astures. Oviedo 1981, asi como para el de sus vecinos los galaicos N. SANTOS, El ejército y la romanización de Galicia, Oviedo 1988.

Estas cuestiones ya han sido tratadas, entre otros, por N. SANTOS y E. CARTES, "Vias de comunicaciónm y romanización del Occidente de Asturias", "/ Congreso peninsular de Historia Antigua, Coimbra 1994, págs. 423ss

8 Ver, entre otros, C. FERNANOEZ OCHOA, "El impacto romano sobre el habitat del Noroeste", BIDEA n. ${ }^{\circ} 120$ (1986) 1099ss.. y M. PASTOR, “El urbanismo y los núcleos de población en el conventus Asturum", Zephyrus 26-27 (1976-1977) 417ss.

9 Vamos a considerar, en primer lugar, su trazado desde el entronque con el concejo de Tineo (explotación aurifera de Lavadoira) hasta la región de Berducedo, centro de cruce de vias antiguas de gran significado, para analizar a continuación el recorrido que desembocaba en la región de San Emiliano y acababa penetrando en el concejo de Grandas de Salime.

10 N. Santos, "La via romana del río del Oro y del Valledor en el concejo de Allande (Asturias)", (en prensa). 
propio concejo allandés ", el elemento definitorio de lo que será y supondrá el proceso de penetración de la organización romana en el marco de dicho territorio y, consiguientemente, de las poblaciones que lo habitaban.

Desde el punto de vista geográfico estaría definido claramente por un conjunto de sierras de cierta importancia: asi, por su margen derecha (en dirección al Puerto del Palo) hallamos en primer término la Sierra de Fonfaraón, que dispone en sus inicios de alturas próximas a los 900 ms. ${ }^{12}$; junto a ello cuenta igualmente con otras que sobrepasan los 1.200 (Cimero o Cimeiro y Hospital), hallándose enclavada también en este ámbito geográfico-territorial la cumbre del Pico del Águila (con más de $1.100 \mathrm{~ms}$. de altitud).

A continuación, y enlazando con la anterior, se encuentra la Sierra de Ablaniego, que sirve en la actualidad, al igual que la de Fonfaraón, como límite de separación entre los concejos de Tineo y Allande, extendiéndose ampliamente en dirección a la región de Bustantigo.

Por su margen izquierda hacia la población actual de Berducedo esta ruta romana, que transitaba por el Puerto del Palo (conocido desde muy antiguo por los paisanos de la zona como «Puerto de las Dorniellas") ${ }^{13}$, no dispone de grandes prominencias montañosas (sierras, cordilleras o montes) si hacemos excepción, y ya en un lugar muy próximo a dicho Puerto, del monte Panchón, que configura la elevación montañosa más pronunciada de todo el concejo allandés (de $1.414 \mathrm{~ms}$. de altitud).

El recorrido correspondiente al Puerto del Palo esta constituido por una altura que sobrepasa los $1.100 \mathrm{~ms}$., contando igualmente a su izquierda con la Sierra de los Lagos, por la que posiblemente transitaría una vía o ramal, que enlazaría a su vez con la que nos disponemos a analizar a continuación en las proximidades de Montefurado ${ }^{14}$.

Para algunos paisanos, conocedores avezados de la geografía y toponimia de la zona, la denominación que reciben tanto la Sierra como el

\footnotetext{
1 Más detalles sobre el significado de este tipo de comunicaciones en N. Santos y A. Garcia LINARES, "Los caminos romanos del valle del Arganza en el concejo de Allande (Asturias)", HAnt 17 (1993) $371 \mathrm{ss}$.

12 Conocidas respectivamente con los nombres de Buño, Buño I y Buño II.

13 En concreto por la cumbre que cruza desde los Hospitales por La Marta (La Morta), El Estreitín, todo el cordal de la Sierra del Palo, etc....

14 Este hipotético camino de comunicación antiguo requiere para la confirmación de su existencia la presencia de restos de época romana que lo corroboren y que desgraciadamente hasta la actualidad no son significativos, en especial si los comparamos con los tan abundantes de la región del Valledor (a este respecto hemos de añadir el hecho de que, en la actualidad, toda esta zona del concejo de Allande se encuentra despoblada)
} 
Puerto del Palo tal vez deriven directamente del término latino palus, que significa lago o laguna (de aguas estancadas); eso explica que la denominación toponímica de dicho paso montañoso (así como de la Sierra en general) tenga mucho que ver con los dos estanques de agua de tiempos romanos existentes en lo alto del puerto del mismo nombre y que serian utilizados como puntos de captación y concentración del agua con vistas al posterior aprovechamiento de los recursos auríferos de la región ${ }^{15}$.

Esta ruta, a la que podemos catalogar como eminentemente minera y que acabaría desembocando con toda seguridad en el litoral cantábrico, atravesaría igualmente todo el concejo de Tineo. Dejando de lado los pormenores de su recorrido en torno a las explotaciones auríferas romanas existentes en Santiago de Cerredo, poco más allá de Lavadoira, y posteriormente en la zona de Naraval-Navelgas, en cuyo caso enlazarian con el concejo de Valdés, donde existen indicios de aprovechamientos auríferos tanto sobre yacimientos primarios como sobre secundarios en el valle de Paredes ${ }^{16}$, nos interesa de manera especial su trazado en las inmediaciones del concejo allandés para comprender su entrada y entronque con el mismo.

II.

Partiendo del concejo tinetense (en concreto de los alrededores de la explotación aurifera romana de Santiago de Cerredo ${ }^{17}$ ), nos encontramos, en primer lugar, con una presa/estanque cuyo destino sería la acumulación de agua, enclavado a unos $750 \mathrm{~ms}$. y destinado sin duda a dichas actividades mineras, por cuyos alrededores transitaba un camino muy antiguo.

Por esta misma zona (Sierra de Fonfaraón) sabemos que en una época posterior (ya en relación con el Camino de Santiago por el interior aprovechando la vía romana que en época romana conectaba los núcleos de población de Lucus Asturum y Lucus Augusti) transitaba el llamado "camino

15 El topónimo La Marta/La Morta, enclavado en las mismas estribaciones de la sierra del Palo, parece relacionarse con unos objetivos similares: embalse de agua destinado a almacenar una cantidad de litros significativa, cuya fuerza hidráulica sería utilizada en las tareas mineras.

16 Ver, por ejemplo, J.L. MAYA, "La cultura castreña asturiana: su etapa romano-provincial», Lancia 1 (1983) 230, donde se conectan con la presencia de centros de población castreña próximos a ella.

17 En cuyo suelo es posible detectar en la actualidad, además de las canalizaciones de agua propias del sistema hidráulico de explotación romana, la presencia de una cueva, tal vez indicio del laboreo correspondiente a mineria de interior (o de prospecciones previas al aprovechamiento intensivo romano de esta zona mineralizable). 
del Hospital», que enlazaría después con la Sierra del Palo; en época medieval ésta sería la ruta utilizada para las peregrinaciones a Santiago de Compostela por el interior, recibiendo por ello la denominación de "camín francés» 18

En sintesis podemos afirmar que, desde la población actual de Fresno en el concejo tinetense, esta vía antigua se dirigiría hacia El Espín, para avanzar a continuación (a una altura que bascula en torno a los $700 \mathrm{~ms}$.) hacia Borres y la Mortera, en cuyos alrededores se han detectado restos de dos explotaciones mineras de oro de época romana sobre yacimiento primario (filón stock-werk); el sistema de aprovechamiento de dichos tajos auríferos se identifica con las explotaciones más comunes utilizadas por los romanos, las constituidas por las cortas a cielo abierto ${ }^{19}$.

Entre ambas poblaciones actuales, un poco en dirección hacia el norte, se halla enclavado el complejo de canalizaciones de agua correspondientes a la explotación romana de Santiago de Cerredo ${ }^{20}$, así como la explotación romana de oro; este yacimiento se cataloga como de tipo filón stock-werk, estando configurado, desde el punto de vista geológico-minero, a base de cuarcita con penetraciones de pirita.

A continuación dicho camino ascendería hacia la zona de Colinas (a una altura cercana a los $750 \mathrm{~ms}$.); este recorrido tan antiguo aún es posible observarlo en la actualidad en ciertos tramos próximos a la carretera, que tal vez se identifiquen plenamente con el trazado correspondiente al primitivo camino de peregrinación de época medieval ${ }^{21}$.

Desde la actual población de Colinas, donde contamos igualmente con vestigios evidentes de aprovechamientos mineros desde tiempos muy antiguos, el trazado de dicha vía ascendería hasta Porciles (a unos $770 \mathrm{~ms}$. de altitud), en cuyo territorio existen indicios de que pudo existir un recinto de

18 No debemos olvidar a este respecto que la zona era conocida como Los Hospitales por hallarse ubicados en la misma varias edificaciones destinadas a la acogida y alojamiento de peregrinos (hospederías).

19 C. Fernádez OChOA, Asturias en la época romana, Madrid 1982, pág. 94. Sin embargo, su descripción de los yacimientos mineros de época romana existentes en la zona es tan simple y reducida que apenas puede servirnos como punto de referencia para nuestros objetivos.

20 Cuyo recorrido fue considerado por Schulz en más de $20 \mathrm{Kms}$. (C. Fernandez OCHOA, Asturias en época romana, pág. 94).

21 Basado a su vez en la vía romana de comunicación que transitaba por dicha zona. A algunos de estos enclaves se refiere precisamente tanto la documentación medieval como la moderna identificándolos con centros de paso existentes en los caminos de ambas épocas, que dispondrían además de sus correspondientes lugares de hospedaje. Cf. J. URiA, "Las fundaciones hospitalarias en los caminos de peregrinación a Oviedo". Anales de la Universidad de Oviedo 1940, pág. 46. 
población castreña de época romana ${ }^{22}$, así como un yacimiento aurífero, de acuerdo con lo que se desprende de la existencia de una "freita" (corte del terreno) bastante pronunciada y de un canal de desague, destinado sin duda a provocar la ruina montium (derrumbe/ desmonte) del terreno perteneciente a la explotación y contribuir a su laboreo.

III.

Seguidamente este camino antiguo enfilaría las estribaciones de la Sierra de Fonfaraón, donde se produciria una bifurcación, de manera que, además del llamado "camino del Hospital" ${ }^{23}$ mencionado más arriba, que transitaría por las estribaciones de dicho relieve montañoso, otro ramal desembocaría en Lavadoira, justamente en el límite existente entre los concejos de Tineo y Allande, a una altura próxima a los $800 \mathrm{~ms}$.

En este enclave territorial existen indicios evidentes de explotaciones antiguas relacionadas con los recursos mineros de oro, cuyas tareas se llevarían a cabo sobre yacimientos primarios (filón stock-werk) ${ }^{24}$ : se trata de cortas a cielo abierto, enclavadas a unos $980-1.000 \mathrm{~ms}$. de altura, que todavía conservan visibles los restos de la canalización del agua ( 3 canales al menos, y muy posiblemente un cuarto) ${ }^{25}$.

Ya en el concejo allandés, y a una altura próxima a los $700 \mathrm{~ms}$., transitaría por un recorrido que enlazaba con el de la actual carretera LuarcaPola de Allande, en concreto por un lugar relativamente cercano a la población de Ferroy, significativo topónimo que tal vez debido a su denominación tengamos que relacionar con extracciones de hierro ya desde esa época romana más antigua ${ }^{26}$.

22 Aunque su vigencia temporal pudo corresponder a un periodo de tiempo reducido, en relación tal vez de manera exclusiva con las actividades vinculadas a los aprovechamientos mineros.

23 Estos parajes son conocidos igualmente con la denominación de "zona de los hospitales" por hallarse enclavados en dicho marco lugares destinados a dar acogida (hospedaje) a personas que hacian este recorrido del Camino de Santiago por el interior.

24 C. Fennandez OChoa (Asturias en la época romana, pág. 94), además de no situar dicha explotación romana en su verdadero contexto geográfico (en el límite entre los concejos de Tineo y Allande) le asigna un nombre incorrecto, sin precisar su importancia y significado.

25 F.J. Sanchez-Palencia y V. Suarez, "La minería antigua del oro en Asturias", Libro de la mina, Gijón 1985, pág. 238.

26 De manera especial si tenemos en cuenta la presencia mo muy alejada, apenas a poco más de $1 \mathrm{Km}$. del emplazamiento de la Pola, de un lugar denominado El Mazo, enclavado en dirección al Puerto del Palo. Tal vez esos productos férricos acabarian convirtiéndose, al menos en parte, en el instrumental laboral necesario para las actividades mineras. 
De esta manera, tras discurrir por el suelo cercano a Penablanca, continuaría descendiendo hasta desembocar en el territorio correspondiente a la actual capital del concejo, dejando a su derecha el poblado castreño ubicado en la zona de Cimadevilla, a una altura aproximada de $560 \mathrm{~ms} .{ }^{27}$.

En este punto sin duda entroncaría con la vía procedente del valle del Arganza, que ya hemos descrito en un trabajo anterior y que gravitaría en torno a San Chuis como núcleo de población más importante, desde el que se controlarian todos los productos mineros extraídos en las explotaciones auríferas de su entorno (entre otras las de Abaniella-lboyo, El Bachicón de Fresnedo, Cárcoas de Cereceda, Villavaser, Figueras...) ${ }^{28}$.

En el ámbito territorial del castro de Cimadevilla se enmarca la explotación minera romana conocida como El Bachicón, en suelo de Fresnedo: enclavada en la margen derecha del arroyo homónimo, afluente del Nisón (tributario del Arganza), se identifica con un yacimiento primario sobre roca (tipo filón stock-werk) a una altura aproximada de $800 \mathrm{~ms}$., correspondiéndose su sistema de explotación con una corta a cielo abierto ${ }^{29}$.

Las labores extractivas se desarrollarian sobre pizarras, cuarcitas, micas y areniscas; de acuerdo con la amplitud del frente de corta de la explotación se removerían varios millones de metros cúbicos de terreno mineralizable ${ }^{30}$. Como testimonio de dichas actividades de tiempos romanos se conservan todavía restos de canales y embalses de agua, sobresaliendo en especial por su significado el hallazgo de un mortero.

Dicha pieza resulta comparable, en su morfología y funciones, a otra descubierta en Cecos (concejo de lbias): se trata en ambos casos de piedras de material duro, que cuentan con varias cazoletas en sus caras más planas, aunque nada tienen que ver con los morteros o lastras de cazoletas que se detectan en ciertos poblados castreños del Occidente de Asturias ${ }^{31}$.

Los denominados "morteros" de Fresnedo y Cecos, descubiertos en las proximidades de sendas cortas a cielo abierto inmersas en el ámbito de

\footnotetext{
2) El recinto castreño de Cimadevilla, en territorio de la Pola, emplazado en la margen izquierda del río Nisón, domina totalmente la capital del concejo y sobre él se erige en la actualidad ef Palacio de los Cienfuegos.

28 Para más detalles remitimos a N. SANTOS y A.GARCIA LINARES, "Los caminos romanos de valle del Arganza en el concejo de Allande (Asturias)", págs. 371 ss.

29 C. FERnANDEZ OCHOA (Asturias en la época romana, pág. 94) lo describe de manera telegráfica e incompleta.

30 Al menos 5 según los cálculos más recientes (ver, por ejemplo, F.J. SÁNCHEZ-PALENCIA y $V$ SÚAREZ "La mineria antigua del oro en Asturias", pág. 238).

${ }^{31}$ Sobre el alcance y sentido de estas últimas piezas remitimos a N. SANTOS, "Significado de las piedras de cazoletas halladas en los castros asturianos", BIDEA n. 111 (1984) 3ss.
} 
la minería de tiempos romanos, constituyen huellas evidentes del lavado y enriquecimiento de la tierra aurífera de dichos yacimientos al integrarse como un elemento más en el proceso de aprovechamiento del mineral ${ }^{32}$.

En la margen izquierda del arroyo de Fresnedo existe una gran acumulación de tierra, en especial muy cerca ya de la Pola, proveniente sin duda de las arenas auríferas de la base de explotación de El Bachicón, cuyos restos y estériles menores (correspondientes a la fase final del proceso de explotación) serían trasladados hasta allí ${ }^{33}$.

Por su parte la mano de obra de dicha explotación aurífera podía proceder, al menos en parte, del poblado de Cimadevilla y/o del recinto castreño de El Mazo (conocido con el nombre de El Castiecho), dada la proximidad existente entre ambos enclaves ${ }^{34}$.

IV.

El recinto de población antiguo de Cimadevilla, ubicado en la margen izquierda del río Nisón, concretamente en un montículo que domina la capital del concejo y sobre el que se halla emplazado en la actualidad el palacio de los Cienfuegos, presenta las caracteristicas naturales propias de un asentamiento poblacional castreño, a pesar de que a simple vista no es posible apreciar la presencia de un sistema defensivo notable (se observa una hondonada, correspondiente sin duda al foso, pero no elementos amurallados) ${ }^{35}$.

La denominación actual de dicho enclave (el topónimo "Cimadevilla») se corresponde con un territorio emplazado por encima de la villa, lo que nos esta indicando posiblemente su origen romano, así como el de la actual capital del concejo ${ }^{36}$.

32 Para más detalles y una comprendión del sentido de dichas piezas en el marco de las explotaciones mineras romanas remitimos a F.J. SANCHEZ-PALENCIA, "Los "morteros" de Fresnedo (Allande) y Cecos (lbias) y los lavaderos de oro romanos en el NO de la Península lbérica", Zephyrus 37-38 (Homenaje a F.Jordá), 1984-1985, págs. 349ss.

${ }_{33}$ En este sentido tal vez topónimos como La Rapigueira (El Rapigueiro) tengan mucho que ver con tales actividades y labores mineras.

34 Igualmente esta fuerza de trabajo pudo ser aportada, al menor en parte, por los habitantes del poblado castreño de Pradiella (El Castiecho) o del existente posiblemente junto a Prada, en cuyo caso su existencia quizás haya que relacionarla exclusivamente con las décadas de aprovechamiento de los recursos de oro por parte romana en la región.

35 Ubicado a unos $540 \mathrm{~ms}$. de altura, estaría integrado en la ruta minera de oro que, desde Pola de Allande, incluyendo o no la Sierra del Palo, se desplazaría hasta la costa, atravesando el territorio del cercano concejo de Tineo (y el de Valdés después).

36 Tal vez ya en una fase avanzada del Imperio. 
En ese contexto temporal correspondiente a las etapas finales del mundo antiguo contamos, a escasa distancia de la Pola, con el topónimo actual de Villafrontú (con anterioridad conocido igualmente como Villafortún), término que parece proceder claramente de villa Fortun(i) o villa Fortun(ati), indicio de la implantación y arraigo de la nueva forma socio-económica de habitat en el entorno de Allande inmediatamente después de la ruina de los asentamientos castreños ${ }^{37}$.

De esta manera el marco territorial del recinto fortificado de Cimadevilla, además de estar encuadrado en el camino proveniente de la cuenca del Arganza, constituiría el punto de confluencia de otras dos vías de comunicación: la que se desplazaba hasta la región minera de Santiago de Cerredo (concejo de Tineo) y la que, por la margen izquierda del río Nisón, ascendía en dirección a la Sierra del Palo.

La primera de ellas continuaba trayecto hacia el importante yacimiento aurifero de Lavadoira (límite de los concejos de Allande y Tineo), tras discurrir cerca de las actuales poblaciones de Ferroy y EI Caleyo ${ }^{38}$.

Desde este recinto de habitat de características castreñas ubicado en Cimadevilla el camino antiguo se desplazaría cerca de la población actual de El Mazo, donde pudo existir un poblado castreño conocido con el nombre de El Castiecho o Los Castiechos; en este lugar hasta hace unas décadas existiría un mazo destinado a la elaboración de piezas de hierro (instrumental laboral y de la vida cotidiana), similar en sus características y estructura al de Besullo en el vecino concejo de Cangas del Narcea.

No debemos olvidar que el camino antiguo seguiría a grandes rasgos la dirección de la carretera Pola-Puerto del Palo (en realidad su denominación es la de Pravia-Lugo) por un trazado más bajo que el actual, es decir más próximo al cauce del río Nisón ${ }^{39}$.

Inmediatamente después, y ascendiendo siempre en dirección a la Sierra del Palo, transitaría por los alrededores de las actuales poblaciones de Colobredo, Peñaseita y La Reigada, hasta alcanzar el lugar en que en la actualidad se bifurca la carretera (ya a más de $800 \mathrm{~ms}$. de altitud) en

\footnotetext{
37 Más detalles sobre estas cuestiones en N. SANTOS y A.GARCIA LINARES, "Las villas romanas en torno a Pola de Allande (Asturias)", Homenaje a F.Presedo, Sevilla 1995, págs. 721ss.

38 Se localizan en la zona significativos topónimos, como Horrio la Cueva y Recuevanos, que parecen relacionarse, directa o indirectamente, con actividades mineras (incluida minería subterránea o de interior), tanto de hierro como de oro.

39 En este sentido por la margen izquierda de dicha corriente fluvial enlazaría la vía que venía por encima de Cimadevilla. Muy posiblemente el recinto castreño de este lugar se conectaría con Los Hospitales a través de un camino.
} 
dirección respectivamente hacia el Puerto del Palo y hacia la región de Bustantigo ${ }^{40}$.

V.

A una altura cercana a los $900 \mathrm{~ms}$. la ruta de comunicación romana se dirigiría hacia la parte derecha de la Sierra del Palo iniciando un ascenso aún más pronunciado hasta alcanzar el lugar denominado Prado de la Vechiga, donde se bifurcaría en una doble dirección: por un lado, hacia su derecha, el trazado se encaminaría hacia Santiellos (por la zona del Estreitín, o muy próximo al mismo) con el fin de llegar a continuación a un distrito eminentemente minero en época romana, como era la región de Bustantigo ${ }^{41}$, mientras que por el otro (hacia la izquierda) recorreria, a una altura que sobrepasaba los $1.100 \mathrm{~ms}$., el territorio situado por encima de la Sierra del Palo.

En el primero de los casos hemos de destacar, en un lugar relativamente próximo al punto de entronque de ambos caminos ( $y$ ya en la parte de allá de la Sierra del Palo tras atravesar El Estreitín), la presencia de un yacimiento minero romano conocido con el nombre de La Marta o La Morta, junto al que se encuentran restos de cultura dolménica, en concreto los dos túmulos que portan la denominación de dicho lugar ${ }^{42}$.

Este topónimo se conecta sin duda con el término latino morta (= muerta) y esta relacionado con las aguas estancadas (embalse del sistema hidráulico romano destinado a la explotación aurífera), de la misma manera que en el marco del concejo allandés encontramos otras denominaciones con las mismas connotaciones mineras antiguas, entre ellas la conocida como Fuente las Mulleres (en Sesto la Fuente) o bien el conocido como Pozo de las Mulleres Muertas (que hemos de identificar con embalses en los que se acumulaban las aguas y por ende en ocasiones estaban en estado

40 Tal vez el trazado actual de ascensión al Puerto del Palo no corresponda, al menos en una parte de su recorrido, con el perteneciente a tiempos romanos sino que hay que ponerlo en relación con el Camino de Santiago de época medieval-moderna.

${ }_{41}$ Aunque en la actualidad no contamos con restos suficientes para confirmarlo plenamente.

42. En este mismo contexto hemos de tener en cuenta que en la cercana Sierra de Fonfaraón se han descubierto abundantes túmulos, destacando los conocidos como túmulo del Chanu del Gamyu, Chanu de la Sierra y Chanu del Buñu, algunos de ellos verdaderos conjuntos tumulares.

Igualmente fueron halladas en la zona hachas de apéndices laterales, y en concreto en Fonfaraón una punta de lanza, fechada en el Bronce Final Atlántico III. Cf. M. A. DE BLAS, La prehistoria reciente de Asturias, Oviedo 1983, pág. 174. 
de putrefacción), esta última en el límite entre los concejos de Cangas del Narcea, Ibias y Allande ${ }^{43}$.

Se trata de un aprovechamiento primario sobre roca (tipo filón stockwerk), cuyo sistema de explotación se identifica claramente con una corta a cielo abierto ${ }^{44}$, enclavado en la margen izquierda del arroyo de Santiellos, ya en el recorrido correspondiente a la vía que conduciría hacia la región minera de Bustantigo, donde tenemos constancia de que los romanos aprovecharían numerosos centros de recursos auríferos, como hemos analizado ya en otro trabajo ${ }^{45}$.

Los problemas surgen, sin embargo, a la hora de concretar con precisión el lugar de habitación (y/o alojamiento) de la mano de obra destinada a trabajar en este centro minero y en el no muy alejado de La Freita: para solucionarlos podemos pensar o bien en la presencia de edificaciones de carácter temporal fabricadas a base de madera (tendejones o barracones) y destinadas a dar acogida a la fuerza de trabajo utilizada en el yacimiento minero de La Marta durante los meses estivales en que se llevarían a cabo dichas labores en la corta minera, o bien en la existencia de un recinto poblacional asentado al pié de la explotación correspondiente a la Fana la Freita, una parte de cuya población se desplazaría diariamente para trabajar en la corta que estamos analizando ${ }^{46}$.

VI.

Desde El Estreitín, al igual que lo había venido haciendo por la Sierra de Fonfaraón a partir del cruce con el concejo de Tineo, cumbreando por

43 Desde La Marta/Morta se detecta la presencia de dos antiguas, una de las cuales avanzaba hasta Lavadoira (tiene su origen en el lugar conocido como Fuente las Mulleres, en concreto en la parte más elevada de la Sierra del Palo), mientras que la otra se desplaza, a un nivel más bajo, hasta Chavallos (Ferroy), muy cerca de la carretera de Luarca.

${ }_{44}$ C. Fernandez OChOA, Asturias en la época romana, pág. 96. No comprendo el motivo por el que dicho yacimiento se incluye, junto con 5 más, en un distrito minero romano que hace corresponder con los ríos del Oro e Ibias.

45 F.J. SANChEZ-PALENCIA y V. SuAREz, "La minería antigua del oro en Asturias", pág. 238. De cualquier forma es posible pensar que este camino acabaría en dicho punto en época romana, mientras que el que conducía a Bustantigo lo podría hacer a través de los recintos castreños de La Garganta de El Castro (Berducedo), el Pico Castro (Arbeyales, Santa Coloma) y uno más, este todavia sin confirmar plenamente, que estaría enclavado en los aledaños de la Braña de Campel (parroquia de Santa Coloma).

Para más detalles remitimos a N. SANTOS, "La vía romana de Berducedo a Bustantigo en el concejo de Allande (Asturias)" (en prensa).

46. En cualquier caso este posible recinto de población castreña rondaría (o incluso sobrepasaria) los $1.000 \mathrm{~ms}$. de altitud, por lo que posiblemente su habitabilidad sería temporal, quedando reducida a la época estival (meses de mayo a septiembre). 
la Sierra del Palo en dirección al Puerto del Palo, hallamos restos de la ruta que enlazaría ambos puntos y que transitaría a escasa distancia de la parte superior del yacimiento romano conocido como Fana o Fanas la Freita, que se corresponde con el lugar denominado El Desmonte: en la actualidad el acceso a dicho centro minero romano se lleva a cabo por la braña del Cabral en dirección a la base correspondiente a dicha explotación de época antigua ${ }^{47}$.

Nos hallamos ante una mezcla de aprovechamientos auríferos realizados tanto en yacimiento primario (sobre roca o filón stock-werk) como en secundario o de aluvión, en ambos casos con un predominio claro de las cortas a cielo abierto ${ }^{48}$; el tipo de aprovechamiento se desarrollaría sobre terrenos auríferos en roca, más o menos alterados por la erosión y por toda una serie de fenómenos meteóricos.

En este sentido se ha calculado, tal vez un poco exageradamente, que los metros cúbicos de terreno mineralizable removido sobrepasarían los 9 millones ${ }^{49}$, resultando en la actualidad bastante visibles los restos de canales de agua destinados a abastecer del líquido necesario a esta ingente explotación.

Por encima de la Fana la Freita se hallaba enclavado en época medieval-moderna un nuevo hospital, conocido con el nombre de Hospital de Valparaíso, sin duda un punto de parada y hospedaje más de los correspondientes durante esas épocas al trayecto correspondiente al Camino de Santiago por estos parajes del interior.

A pesar de todo resulta difícil precisar el lugar de alojamiento de la mano de obra necesaria para las labores y actividades mineras de dicho yacimiento aurífero, encontrándonos con un problema similar al del caso de La Marta: dado el enorme volumen del terreno mineralizable desmontado, lo que haría necesaria sin duda la presencia de una fuerza de trabajo abundante durante varias décadas, nos inclinamos por la existencia de un poblamiento castreño en la parte más baja de dicha explotación, ya que resulta problemático pensar que dicha mano de obra afluyera por ejemplo del recinto poblacional conocido como Pico el Castro, emplazado en Arbeyales (parroquia de Santa Coloma) a causa de la distancia existente entre ambos enclaves ${ }^{50}$.

\footnotetext{
47 Para Schulz únicamente se conservaria visible el canal de alimentación de agua de la explotación.

is C. Fernandez Ochoa, Asturias en la época romana, pág. 96, sin precisar nada sobre la importancia y caracteristicas que envolvieron a dicha corta minera en época romana.

49 F.J. SANCHEZ-PALENCIA y V. SuAREZ, "La minería antigua del oro en Asturias", pág. 233.

50) Tal vez, al menos de forma temporal, pudieron existir algunos cobertizos o tendejones de madera destinados a dar acogida, al menos parcialmente, a los componentes de dicha mano de
} 
VII.

A partir de aquí, siguiendo la cumbre de la Sierra del Palo, el camino romano alcanzaría el collado del Palo, donde, a más de $1.100 \mathrm{~ms}$. como en el caso anterior, encontramos sintomas evidentes de explotaciones mineras romanas: destaca sobre todo un embalse de proporciones amplias, así como otro más reducido, divisándose al mismo tiempo abundantes canales de agua destinados a las tareas mineras visibles en la ladera occidental de dicho relieve montañoso ${ }^{51}$.

El aporte de agua, además del proveniente de la lluvia, se acarrearía desde la parte más elevada de la Sierra del Palo, yendo a desembocar en los dos embalses mencionados; una vez concentrado allí, se distribuiría, de acuerdo con las necesidades, en las explotaciones de una y otra vertiente de la Sierra ${ }^{52}$.

Desde el punto de vista geológico esta región del Puerto del Palo se identifica con una zona de rocas fácilmente deleznables, que sería desmontada por los romanos en amplias explotaciones a cielo abierto, al igual que sucedería, en este mismo ámbito del concejo allandés, en el caso del Valledor y Bustantigo ${ }^{53}$.

Este aprovechamiento aurífero sobre yacimiento primario requeriría la presencia de mano de obra empleada como fuerza de trabajo en las actividades laborales del lugar, aun en el caso de que la explotación de dichos recursos económicos solamente se llevase a efecto durante los meses del año de mejor temperatura; tal vez por ello es posible que dicha fuerza de trabajo encontrase cobijo en un conjunto de tendejones o cobertizos de madera, que fácilmente podían ser abandonados durante el periodo invernal ${ }^{54}$

obra, sobre todo si pensamos en la etapa (apenas unas décadas) de intenso aprovechamiento de los recursos auriferos del yacimiento.

51 Este puerto de montaña es conocido en la diplomática medieval (A. Floriano CumBRERO, Libro Registro de Corias, Oviedo 1950, 1, pág. 73) como Portum Aberturas, siendo citado igualmente en el siglo XVIII por parte de Antonio María QuEIPO Y Ron como Freita de las Aberturas.

${ }_{52}$ La canalización de las aguas se puede rastrear a to largo de varios $\mathrm{Kms}$., en algunos casos (como en el de Lavadoira por ejemplo) de un trazado que sobrepasa los 20.

53 F.J.Sanchez-PAlencia y V. SuÁrez, "La mineria romana del oro en Asturias», pág. 222. Para una descripción más detallada de lo que rodeó a esta corta minera remitimos a P.R. LEWIS y G.D.B. JoNES, «Roman Gold-Mining in North-West Spain», JRS 60 (1970) 178-180.

${ }_{54}$ Posiblemente haya que pensar en la existencia de un recinto de población castreña ubicado en los alrededores de Montefurado, que aportaría la fuerza de trabajo necesaria para dichas labores mineras. 
VIII.

Desde el Puerto del Palo el trazado viario seguiría la dirección correspondiente a la margen derecha de la carretera actual: iniciando el descenso hacia Montefurado, por un recorrido que en buena medida se identifica con el correspondiente a la vía de comunicación de nuestros días, el camino antiguo enlazaría con la explotación minera romana conocida como Cueva de Xuan Rata, localizada en la vertiente occidental del Puerto del Palo y a una altura que ronda los $950 \mathrm{~ms} .{ }^{55}$.

Nos hallamos en este caso nuevamente ante un yacimiento primario sobre roca (filón stock-werk), en el que parece combinarse desde el punto de vista técnico-minero el lavado superficial con el sistema de explotación constituido por el minado-pozo ${ }^{56}$.

En cualquier caso se trata de un claro ejemplo (prácticamente el único, o cuando menos el más significativo de todos los correspondientes a este distrito que estamos analizando) de minería subterránea; en dicho contexto minero destaca la presencia de galerías y pozos, lo que constituye un sistema de aprovechamiento de los recursos auríferos mucho menos frecuente en todo el cuadrante nordoccidental de la Península Ibérica que el de las cortas a cielo abierto ${ }^{57}$.

Se recurre a este tipo de explotación con el fin de beneficiar el aurum canaliense o canalicium de Plinio ${ }^{58}$, puesto que las vetas o filones se iban excavando mediante la apertura de canales o galerías subterráneas, configurando así un procedimiento que sería aplicado únicamente en los yacimientos mineros cuyos filones ofrecían una potencia y una ley considerables ${ }^{59}$.

Por lo que se refiere a la mano de obra hemos de tener en cuenta que el tajo de dicha explotación se hallaba a una altura elevada, lo que puede llevarnos a pensar en la existencia de un aprovechamiento minero de carácter temporal, en el que la fuerza de trabajo pudo encontrar alojamiento en una

\footnotetext{
55 Schulz aporta noticias acerca de la presencia de una gran explotación, cuya acequia (o canal de desagüe) perforaría la línea divisoria de los ríos Valledor y Castelio sin poder definir en ningún caso qué tipo de mineral sería explotado en tiempos antiguos.

5f C.Fernandez OCHOA, Asturias en la época romana, pág. 96. No hace alusión alguna, sin embargo, a otras explotaciones próximas conocidas con esta misma denominación (como veremos más adelante).

57 P.R. LEWIS y G.D.B. JONES, «Roman Gold-Mining in North-West Spain», págs. 179-180.

58 N.H. 33.68.

59 Una explicación mucho más detallada puede observarse en C.DOMERGUE, "Á propos de Pline, Naturalis Historia 33,70-78 et pour illustrer sa description des mines dor romaines d'Espagne", AEA 45-47 (1972-1974) 519 y 522.
} 
serie de edificaciones de madera (cobertizos o tendejones), cuya vigencia temporal y mantenimiento en uso no serian excesivamente prolongados ${ }^{60}$.

Muy próximas a la Cueva de Xuan Rata, y sin duda enlazadas igualmente por esta vía romana que estamos analizando, se encontraban dos nuevas explotaciones mineras de oro trabajadas sobre yacimiento primario (filón stock-werk) a una altura aproximada de 950-1.000 ms., conocidas respectivamente con los nombres de Cortas de Xuan Rata I y II y enclavadas en los alrededores de Montefurado ${ }^{61}$; en este caso resultan totalmente visibles en la actualidad los restos de los canales correspondientes a las conducciones de agua destinadas a ser utilizadas en los tajos de las respectivas explotaciones.

Por lo que concierne a la mano de obra necesaria para completar dichas actividades mineras aún no podemos concretar con seguridad su procedencia, pudiéndose pensar en varias soluciones: o bien en que estaría alojada en barracones (tendejones o cobertizos de madera) durante los meses en que se llevarían a cabo dichas labores en las cortas, o bien que existiría un poblado castreño, de dimensiones más bien reducidas, enclavado en las inmediaciones de Montefurado, que serviría como alojamiento de la fuerza de trabajo precisa para llevar a cabo tales actividades ${ }^{62}$.

IX.

A continuación el recorrido de esta vía de comunicación romana atravesaría la carretera actual y se desplazaría por su parte izquierda hasta las inmediaciones de Montefurado, enclavado en la margen derecha del arroyo del Forno, tributario a su vez del río del Oro; el embalse de agua correspondiente al yacimiento aurífero próximo a dicho lugar se hallaría enclavado en la parte izquierda, observándose con total nitidez la presencia de canales de conducción de agua.

Se trata de una explotación en la que se mezclan tanto las labores sobre yacimiento primario (roca) como sobre secundario (aluvión), teniendo

60 A pesar de ello tampoco sería descabellado pensar en que dicha fuerza de trabajo podía proceder, al menos en parte, del recinto fortificado antiguo conocido con el nombre de $\mathrm{El}$ Cuturuyón de San Pedro, en territorio correspondiente a la parroquia de Lago.

if F.J.SÁNCHEZ-PALENCIA y V.SUÁREZ, "La mineria antigua del oro en Asturias", pág. 238 y mapa de págs. 234-235.

62 Es posible que incluso el recinto habitacional denominado El Cuturuyón de San Pedro aportara el personal necesario para estas tareas de carácter temporal, que se verian cortadas en el transcurso de la estación invernal. 
constancia de la presencia de minería subterránea o de interior en una cueva de varios metros de profundidad existente en la falda del monte ${ }^{63}$.

En cuanto a la mano de obra de esta corta minera tal vez haya que pensar en la presencia de edificaciones de madera de carácter temporal, o bien en un hipotético emplazamiento castreño de vigencia temporal escasa en un lugar muy próximo, que podía abastecer al mismo tiempo de fuerza de trabajo a las explotaciones mineras del Puerto del Palo, así como a las cortas de Xuan Rata I y Xuan Rata II.

Siguiendo aproximadamente el mismo recorrido que el correspondiente a la actual carretera de Pola de Allande a Grandas de Salime el camino antiguo discurriría junto a la zona minera conocida como Fuente de las Mulleres, donde se ubica un gran embalse de agua y una ramificación de varios canales que entroncan con el mismo: enclavada en torno a unos $1.000 \mathrm{~ms}$. de altitud, su emplazamiento se halla próximo al lugar denominado Sesto de la Fuente, habiendo sido identificada con un yacimiento primario sobre roca ${ }^{64}$.

Nos encontramos ante unos restos de aprovechamiento minero comparables a los que corresponden al llamado Pozo de las Mujeres Muertas, emplazado en el límite entre los concejos de Pola de Allande, Ibias y Cangas del Narcea (en este caso a una altitud cercana a los $1.100 \mathrm{~ms}$.); dicho punto geográfico coincide más o menos con lo que constituye el origen de la vía romana de comunicación que transitaba por el río del Oro en el valle del Valledor ${ }^{65}$.

Por lo que se refiere a la mano de obra utilizada en dicha explotación minera su relativa proximidad a Montefurado parece vincular este centro de aprovechamiento aurífero con el hipotético recinto de habitat castreño existente en dicho lugar, a pesar de que hasta la fecha resulta problemática su localización ${ }^{66}$.

\footnotetext{
63 J.L. MAYA, «La cultura castreña asturiana: su etapa romano-provincial», pág. 230. No debemos olvidar en cualquier caso que la toponimia del lugar obedece precisamente a la perforación de la montaña para permitir el paso del agua de una parte a otra de la misma con el fin de facilitar las tareas mineras de la zona en época romana.

64 F.J. Sánchez-PALENCIA y V. SuAREZ, “La minería antigua del oro en Asturias", pág. 238.

65 La amplitud de cortas de explotación minera (conocidas como grobas en dicha región) requeriria la presencia de una comunicación fluida entre los diversos yacimientos de aprovechamiento aurífero.

El estudio monográfico pormenorizado de esta región aurífera romana lo hemos llevado a cabo en otro trabajo. Cf. N. SANTOS, "La vía romana del río del Oro y del Valledor en el concejo de Allande (Asturias)", (en prensa).

66 No podemos descartar la presencia de barracones de madera, que podrian servir temporalmente de alojamiento, a manera de cobertizos, a buena parte del personal laboral utilizado en dichas actividades mineras.
} 
$X$.

A continuación, abandonando poco a poco las estribaciones correspondientes a las Sierras del Palo y de los Lagos, y siguiendo siempre más o menos la dirección que corresponde a la carretera actual, la ruta antigua descendería desde la cumbre hacia El Couso: el trazado cruzaba la carretera moderna y discurria, casi paralela a la misma (apenas unos metros por encima) a la derecha de la actual calzada.

Tras remontar la cumbre nuevamente, discurriría junto a la actual población de Lago, cuya denominación toponímica quizás obedezca precisamente a la laguna, charca, lago o embalse que existe en dicho lugar, que se halla inmerso en el contexto de la explotación minera de oro conocida como Carcabón de Orúa ${ }^{67}$.

Se corresponde con un aprovechamiento aurífero sobre yacimiento primario o roca (filón stock-werk), enclavado en la margen derecha del río del Oro, a una altitud aproximada de $900 \mathrm{~ms}$., cuyo sistema de explotación se identifica con minería a cielo abierto ${ }^{68}$.

De acuerdo con las indicaciones de Schulz en este lugar se beneficiaría pirita de hierro aurífera en filones de cuarzo, abasteciéndose este tajo de explotación mediante el agua procedente del mismo canal o conducto que llegaba hasta la Cueva de Xuan Rata ${ }^{69}$.

La problemática planteada por la mano de obra parece tener mejor solución en este caso que en otros anteriormente analizados, puesto que sin duda el centro de aprovechamiento minero de época romana estaría unido mediante una vía de comunicación (o un ramal cuando menos) con el recinto poblacional castreño denominado El Cuturuyón, emplazado en el territorio correspondiente a la actual población de San Pedro, perteneciente igualmente a la parroquia de Lago ${ }^{70}$.

Este poblado castreño de tiempos romanos, conocido con el nombre de El Cuturuyón, se hallaba ubicado a una altitud que apenas sobrepasaría

67 En J.L. MAYA (“La cultura castreña asturiana: su etapa romano-provincial», pág. 230) la encontramos catalogada como Carcabón de Oruga, posiblemente por error.

68 F.J. Sanchez-Palencia y V. SuAREZ, “La minería antigua del oro en Asturias", pág. 238 y mapa págs. 234-235.

69 C. Fernandez OChoa, Asturias en la época romana, pág. 96. No debemos olvidar que en la parte superior de la población actual existen restos de un lago (que daría origen al topónimo), que muy bien pudo servir como centro de recepción del agua (estanque/ embalse) para estos menesteres.

70 Es posible pensar que, desde este punto, pudo arrancar un camino antiguo que, tras atravesar por Arbeyales, Santa Coloma y El Rebollo, desembocaria en las explotaciones mineras romanas de los alrededores de Bustantigo. 
los $800 \mathrm{~ms}$., teniendo constancia igualmente de la presencia de un poblamiento más antiguo en la zona a través de restos correspondientes a la cultura dolménica, como los dos túmulos de Penas por ejemplo ${ }^{71}$.

Sin embargo, en lo que respecta al personal laboral empleado en la explotación del Carcabón de Orúa no podemos desdeñar la presencia, más o menos abundante, de mano de obra procedente del Castello de Berducedo, sobre todo si tenemos en cuenta que entre Lago y Berducedo (y bastante cercana al poblado fortificado de Castello) existiría otra explotación minera de oro ${ }^{72}$.

Seguidamente este camino del Puerto del Palo en dirección a Grandas de Salime atravesaría junto a la explotación aurífera de Lago, enclavada igualmente en la margen derecha del río del Oro, en un enclave casi equidistante de las actuales poblaciones de Lago y Berducedo ${ }^{73}$.

Se corresponde con un aprovechamiento minero de oro sobre yacimiento secundario o de aluvión ${ }^{74}$, cuya mano de obra podía proceder del poblado castreño conocido con el nombre de Pico Castello, emplazado junto a la población actual de ese mismo nombre, a $1 \mathrm{Km}$. aproximadamente al Nordeste de Baldedo, en territorio correspondiente a la parroquia de Berducedo ${ }^{75}$.

Por consiguiente la vía antigua, desde el emplazamiento de Lago, discurriría por la parte más elevada del cordal, siempre a la derecha, aunque próxima, al trazado de la carretera actual que cumbrea, hasta desplazarse junto al poblado castreño de Castello, que constituye un ejemplo típico de los recintos fortificados de época romana en la región asturiana, y más en concreto en el territorio allandés situado más allá del Puerto del Palo.

$X I$.

Las características más significativas y propias del recinto habitacional de Castello se hacen extensibles al resto de los ya enumerados, así como

J.M. Gonzalez, Historia de Asturias Ayalga, 2: Asturias protohistórica, Salinas 1978, pág. 216

72 Incluso es posible pensar que esta fuerza de trabajo pudo aportarse desde alguno de los pequeños centros de población antigua que existirian en torno a las actuales poblaciones de Carcedo (en cuyo territorio existen indicios de aprovechamientos mineros de época romana: una o dos cortas integradas en la misma explotación) o de Armenande.

73 J.L. MAYA, «La cultura castreña asturiana: su etapa romano-provincial», pág. 230.

74 F.J. Sanchez-Palencia y V. Suarez, "La mineria antigua del oro en Asturias», pág. 238.

75 Resulta fácil suponer que la vía de comunicación antigua transitaría por este punto, al tiempo que un ramal secundario se desplazaría hasta el otro poblado fortificado de Berducedo, conocido con el nombre de La Garganta de El Castro. 
a los que vayamos describiendo en las páginas siguientes: ante todo hemos de destacar que, aunque no pertenecería en realidad ya al territorio habitado por las comunidades de los pésicos, nos ofrece unas peculiaridades constructivas mnuy parecidas a las más sobresalientes de los poblados de los mismos, como podemos observar por ejemplo en el castro de San Chuis ${ }^{76}$.

El Pico Castello configura el emplazamiento del poblado de su mismo nombre, estando ubicado en un montículo redondeado en el borde septentrional del cordal de Berducedo, a una altura aproximada de unos 800 ms. ${ }^{77}$ : se distingue a simple vista una gran cantidad de piedra acumulada en ciertos lugares del recinto, de manera especial en la zona que constituye el punto de acceso más fácil al mismo.

A pesar de hallarse bastante deformado en la actualidad como consecuencia de su conversión en terreno de laboreo agrícola, este recinto poblacional, en el que la pizarra aflora en algunas de sus partes, dispondría de elementos muy bien definidos, como por ejemplo un escarpe de unos 4 ms. de altura y más de 500 de perímetro, así como una muralla construida a base de piedra; a ello hemos de añadir un segundo escarpe y una segunda muralla de menor profundidad y altura respectivamente que los anteriores, así como, finalmente, un recinto interior de forma ovalada (en la parte sureste de dicho recinto la muralla se ensancha, detectándose al mismo tiempo un gran cúmulo de piedras, cuyos restos pertenecerian posiblemente a un refuerzo de la misma) ${ }^{78}$.

Como elemento más significativo de este recinto de población castreña de época romana, cuyo origen remontaría sin duda a tiempos anterromanos, contamos con el único ejemplar de arracada de oro hallado hasta la fecha en suelo asturiano, descubierto en concreto en la zona inferior de acceso al poblado por parte de los buscadores de tesoros ${ }^{79}$.

Esta joya de la orfebrería castreña se identifica con un pendiente hueco elaborado a base de oro y que esta constituido por dos laminillas en forma de creciente lunar, soldadas en sus bordes; dichas láminas se hallan rema-

\footnotetext{
76 J.M. GonzÁlez, Historia de Asturias Ayalga 2: Asturias protohistórica, pág. 217.

77 Su enclave destaca, a modo de contrafuerte, sobre la margen izquierda del arroyo de Rozadas, afluente a su vez del río Navia.

78 Este emplazamiento domina un territorio bastante amplio a su alrededor, constituyendo un asentamiento característico de una región explotada por los romanos desde el punto de vista de los recursos mineros.

79 J.M. GonzAllez y J. Manzanares, "Arracada de oro procedente de un castro de Berducedo (Allande)", AEA 32 (1959) 115ss.
} 
tadas a su vez en sus extremos por dos coronillas, en las que engancharía la cadena de colgar ${ }^{80}$.

Por consiguiente la vía romana del Puerto del Palo enlazaria la conocida como explotación minera romana de oro de Lago con el recinto poblacional de El Pico Castello, enclavado en la localidad de ese mismo nombre (correspondiente a la parroquia de Berducedo), desplazándose a continuación hasta el otro recinto de población antigua ubicado en esta misma zona, el denominado La Garganta, ubicado en el lugar conocido con el topónimo de El Castro ${ }^{81}$.

Localizado en las últimas estribaciones del cordal de Berducedo, y casi en el arranque de las elevaciones montañosas de la Sierra de Muriellos, se encuentra ubicado a una altura entre los 700 y 800 ms. ${ }^{82}$.

En cuanto a su funcionalidad parece lógico suponer que este recinto poblacional de época castreña estaría en relación con el aprovechamiento de los recursos auríferos de sus alrededores, a pesar de no haberse detectado hasta la actualidad la presencia de yacimientos pertenecientes con claridad a tiempos exclusivamente romanos ${ }^{83}$.

De cualquier forma podemos afirmar que el territorio cercano a estos dos centros de población castreña de la parroquia de Berducedo (El Pico Castello y La Garganta de El Castro) cumplirian unas funciones muy similares a las que llevarían a cabo los dos recintos fortificados existentes en esa misma época en torno a Besullo en la cuenca del río Arganza (en la proximidad del límite entre los concejos de Cangas del Narcea y Allande): en ambos casos se trataría de enclaves que constituirían cruces de caminos, tanto antiguos como modernos, teniendo por ello además la finalidad de controlar las explotaciones mineras de oro de sus alrededores ${ }^{84}$.

Así pues, esta ruta romana, tras atravesar la carretera actual junto a Cabornel, tomaría dirección izquierda hasta Berducedo, donde se produciría

${ }_{80}$ La decoración se encuentra realizada a base de filigrana y granulado, siendo más rica y recargada en el anverso que en el reverso de la pieza. Cf. N. SANros, "Introducción al estudio del arte castreño en Asturias", BIDEA n. ${ }^{\circ}$ s 109-110 (1983) 398-399.

81 Tal vez nos encontremos en este caso con el tramo que constituye el punto de arranque del camino romano que desembocaba en la región minera de oro de Bustantigo y penetraría posteriormente en el concejo de Villayón.

82 J.L. MAYA, "La cultura castreña asturiana: su etapa romano-provincial», pág. 228.

83 J.M. Gonzalez, Historia de Asturias Ayalga 2: Asturias protohistórica, pág. 216.

84 En este sentido uno de estos dos recintos de habitat (tal vez el segundo de ellos, aunque podrian variar de acuerdo con las épocas) pudo servir como receptáculo de los productos extraidos en los yacimientos mineros de sus cercanías. No obstante, en ambos casos es posible observar con mayor claridad su función de centro de vias de comunicación antiguas. 
una bifurcación, de modo que el ramal que se desplazaba hacia el Valledor adquiriría una importancia mayor que el que se encaminaba en dirección a Grandas de Salime.

XII.

Desde el Castello de Berducedo la dirección que tomaría la vía de comunicación antigua de Pola a Grandas se encaminaría, siempre ya en línea descendente, hacia el pueblo actual de Teijedo (Teixedo), en cuyas proximidades existiría posiblemente una explotación minera sobre yacimiento primario (filón stock-werk), cuya mano de obra encontraría alojamiento en el recinto poblacional que acabamos de mencionar ${ }^{85}$.

De esta manera la ruta romana seguiría la margen izquierda del arroyo de Rozadas, alcanzando en primer término el suelo correspondiente a la actual población de Buslavín, para desplazarse seguidamente hacia Villadecabo y La Quintana (topónimo de época romana), y desembocar finalmente junto al poblado castreño de San Emiliano; todo ello antes de continuar su recorrido y penetrar en el territorio correspondiente al concejo de Grandas de Salime ${ }^{86}$, una vez atravesado el lugar conocido en nuestros días con la denominación de Murias, topónimo que nos pone en conexión con la existencia de restos muy antiguos (cuyo origen hay que hacer remontar, en cuanto a su fecha, tal vez a tiempos romanos).

En cuanto al recinto castreño de San Emiliano constituye un poblado fortificado que nos presenta, además de los naturales, escarpes y defensas de factura artificial ${ }^{87}$, hallándose enclavado a una altura que apenas sobrepasaría los 300 ms.; al margen de sus características morfológicas, que no es posible distinguir con claridad, los principales interrogantes en torno a dicho centro surgen a la hora de asignarle una finalidad eminente o exclusivamente ganadera o, por el contrario, una vinculación directa con posibles aprovechamientos mineros de oro de tiempos romanos, que hasta la fecha no se han podido detectar con claridad ${ }^{88}$.

8.5 Es posible que esta corta apenas fuese trabajada por los romanos durante un corto espacio de tiempo.

${ }_{86}$ A pesar de un reconocimiento exhaustivo de la zona no hemos podido encontrar indicio alguno de tiempos antiguos, incluidos los elementos propios de la minería aurifera romana (embalses de agua, canales de desagüe, cortas y tajos mineros de explotación...).

87 Gran Enciclopedia Asturiana 1, Gijón 1970, pág. 180.

88 Merece la pena contemplar en la población de San Emiliano las raices medievales que caracterizan todas las construcciones del caserío actual, cuyos origenes posiblemente remontan a 
$X I I I$.

Como corolario de cuanto acabamos de exponer en las páginas precedentes se hace preciso afirmar, en primer lugar, que los restos de yacimientos antiguos situados a ambas márgenes de la ruta que en tiempos romanos conducía desde lo que hoy es Pola de Allande ${ }^{89}$ en dirección a Grandas de Salime nos permiten descubrir algunas de las caracteristicas que en aquella época denotaban un significado más sobresaliente con respecto al habitat castreño y a las actividades económicas de dicha región (en este segundo caso sobre todo en relación con el sector minero pero también, en menor medida, con el ganadero).

Por lo que respecta a los recintos de población, cuya vigencia se extendería durante las dos primeras centurias de nuestra era, hemos de afirmar que su número sería posiblemente más amplio que el que tradicionalmente se venía adjudicando al conjunto del concejo de Allande(a lo sumo 8 en todo este territorio); de cualquier forma estos núcleos de habitat castreño que acabamos de reseñar nos ofrecen todo un conjunto de elementos característicos y significativos en cuanto al momento de su origen (prerromanos, romanizados o de nueva planta), tiempo de ocupación, actividades económicas (mineras y/o ganaderas), con las que se vinculaban..., que aparecen resumidos en el siguiente esquema:

1. Castro de Cimadevilla (La Pola) $P R \vee M$ ? (hierro)(topónimos)

2. EL (Los) Castiecho(-os)(EL Mazo)P?R M (hierro)

3. Castro de la Freita (Corona?) R M N.P.

4. Alrededores de Montefurado ? R M N.P.

5. El Cuturuyón de San Pedro(Lago)P?R M?G

6. El Pico Castello de Berducedo $P R \vee M \quad G$

7. La Garganta de El Castro (Berducedo)

8. Castro de San Emiliano

\author{
P?R $V M ? G$ \\ $P R G M ?{ }^{90}$.
}

la época histórica más antigua de la zona. Como Castello, correspondiente a San Emiliano, aparece mencionado por J.M. GONZALEZ ("Vestigios de siete castillos medievales asturianos", Archivum 22 (1972).

89 O, más bien, desde sus alrededores, puesto que el camino romano de mayor importancia y significado no discurriría más que de forma tangencial (un ramal) por el territorio correspondiente en la actualidad a la capital del concejo allandés. En realidad sería la sierra de Fonfaraón el marco de dicho camino de comunicación, que, enlazando desde el concejo de Tíneo, serviria de base material como infraestructura viaria para el posterior trazado del Camino de Santiago por el interior.

90 Siglas explicativas: $\mathrm{P}=$ poblado de origen prerromano; $\mathrm{R}=$ poblado de época romana o romanizado; $M$ = centro vinculado a tareas mineras; $G$ = conectado con actividades ganaderas; N.P. = recinto fortificado de nueva planta; $V=$ cruce de vías de comunicación; ? = dudoso. 
Hasta la fecha no hemos podido detectar en este área geográfica la presencia de poblados castreños de tiempos prerromanos que serían abandonados en los años inmediatos a la conquista romana del Norte peninsular ${ }^{91}$; sin embargo, resulta evidente la utilización de algunos de ellos durante los siglos de presencia romana (acompañada de la remodelación correspondiente de sus estructuras constructivas) como consecuencia de las labores y actividades económicas nuevas, vinculadas a la minería extractiva del oro ${ }^{92}$.

Junto a las motivaciones de carácter económico-minero (únicamente el posible castro o corona de la Freita tendría una finalidad minera exclusiva y absolutamente constatada), otros centros de habitat castreño encerrarian, desde el punto de vista económico, unos objetivos mixtos, estando en conexión dichos enclaves con el sector ganadero mayoritariamente y con el sector minero como complementario en mayor o menor medida ${ }^{93}$.

Algunos de tales poblados fortificados se corresponderian con recintos de nueva planta, erigidos ya en tiempos romanos con la finalidad casi única (o exclusiva en ciertos casos) de explotar los recursos mineros de sus proximidades. Al parecer únicamente el Castro o Corona de la Freita cumpliría estrictamente estos requisitos, mientras que otros ampliarían en tiempos romanos el espacio habitable de que ya disponían en época prerromana ${ }^{34}$.

De acuerdo con esto algunos recintos fortificados correspondientes a la vía romana de Pola de Allande a Grandas de Salime pudo haber cumplido a lo largo de su existencia funciones de carácter estratégico-militar y de control de una amplia zona territorial, estando vinculados al mismo tiempo con el desarrollo histórico de la misma como centros de confluencia de varios caminos antiguos ${ }^{95}$.

$X I V$.

En lo que concierne a los aprovechamientos mineros próximos a ambas márgenes del recorrido de esta vía de comunicación antigua (conectados

91 Quizás porque sus construcciones tendrian como materia prima principal la madera, tan abundante en la región.

92 Como ejemplos podemos destacar el castro de Cimadevilla, El Cuturuyón de San Pedro, El Pico Castello de Berducedo y el Castro de San Emiliano.

93 Entre ellos El Cuturuyón de San Pedro, El Pico Castello de Berducedo, La Garganta de El Castro y el castro de San Emiliano.

94 En esta situación se hallarian, por ejemplo, los núcleos de habitat castreño de Cimadevilla, el Pico Castello en Berducedo y San Emiliano.

95 Tales objetivos los desarrollarían seguramente, además del castro de Cimadevilla, los dos poblados existentes en la parroquia de Berducedo (EI Pico Castello y La Garganta de El Castro), o cuando menos uno de ellos. 
directa 0 indirectamente con ella), que sobrepasarían la decena, nos presentan un conjunto de características que en síntesis tratamos de resumir en el siguiente esquema-cuadro:

1. Lavadoira (límite concejos Allande-Tineo)

2. La Marta (Puerto del Palo)

$P \quad C$

3. Fana la Freita

$P \quad C \quad E$ ?

4. Zona del Puerto del Palo

5. Cueva de Xuan Rata

$\begin{array}{lllll}P & S & C & E\end{array}$

6. Cortas de Xuan Rata I y II

$\begin{array}{llll}P & C(+) \quad E(\text { dos })\end{array}$

7. Montefurado

$P$ C C $\quad M$

$P$ C C $\quad E$

8. Fuente de las Mulleres (Sesto la Fuente)

$P$ S $C$ E $M$

9. Carcabón de Orúa (próximo a Lago)

10. Lago (entre Lago y Berducedo)

11. Teijedo

$P \quad C(+) \quad E$

$P \quad C$

$S$

Sobresale, en primer lugar, el hecho de que tales labores mineras se llevarían a cabo mayoritariamente sobre yacimientos primarios, si hacemos excepción de los casos correspondientes a La Fana la Freita y Montefurado (en las que se combinarían actividades sobre primario con otras sobre secundario), asi como la corta minera de Lago (al parecer llevada a cabo exclusivamente sobre yacimiento secundario o de aluvión).

El sistema de explotación utilizado en estos centros de aprovechamiento minero se identifica básicamente con las cortas a cielo abierto, ofreciéndonos toda una variedad de formas en conexión con las peculiaridades geológicas de cada yacimiento (desde las de tipo concha a las longitudinales). En este contexto solamente en algunas ocasiones aisladas parece haberse recurrido a otras técnicas o mecanismos de extracción distintas, destacando la minería subterránea o de interior ${ }^{97}$.

De cualquier forma resulta extraordinariamente difícil concretar la cantidad de millones de metros cúbicos de terreno mineralizable que serían removidos en el ámbito de las explotaciones mineras de oro que flanqueaban esta via de comunicación, que enlazaba durante la Antigüedad Pola de Allande con Grandas de Salime: haciendo un cálculo meramente aproximativo podemos

96 Siglas explicativas: $\mathrm{P}=$ yacimiento primario (sobre roca); $\mathrm{S}=$ yacimiento secundario (generalmente aluvión); $C=$ presencia de canales de agua o acueductos; $E=$ embalse de agua; + = presencia de otros centros de aprovechamiento minero, canales o embalses; $M$ = minería subterránea o de interior; ? = restos de atribución temporal insegura.

97 Como sucedería, por ejemplo, en el caso de la Cueva de Xuan Rata o de Montefurado, en este segundo caso tal vez como actividad previa a la puesta en explotación del macenismo técnico que encerraba la ruina montium a pequeña escala. 
pensar que, si solo en la Fana de la Freita se removerían unos 9 millones de metros cúbicos de tierra aurífera, en el resto de los aprovechamientos de tiempos romanos (otra decena al menos) se beneficiarian en torno a 8-10 millones de metros cúbicos, por lo que en su conjunto lo serían aproximadamente entre 15 y 20 millones.

Teniendo presentes estas cifras resulta posible acercarse a la cantidad de kilogramos de oro conseguidos a lo largo de las décadas en que tales yacimientos serían aprovechados por parte de la administración romana; de acuerdo con ello creemos que hay que pensar que dicha cantidad rondaría al menos los $3.000 \mathrm{Kgs}$. dada la potencia y ley de los yacimientos trabajados en dicha región (unos 2 gramos de oro por tonelada métrica de terreno mineralizable aprovechado por los romamos) ${ }^{98}$.

$X V$.

Por lo que respecta al momento de aprovechamiento de tales recursos auríferos quizás tengamos que identificarlo con la etapa final o mediafinal de la presencia romana en el concejo y su interés económico por la zona; debido a ello creemos que las actividades laborales vinculadas con estos tajos mineros se corresponderían ya con el siglo $\|$ de nuestra (probablemente durante toda su primera mitad al menos). A ello hemos de añadir además el hecho de que se trata en su mayor parte de yacimientos primarios, explotados y beneficiados por los romanos como norma general en una fase posterior a los secundarios.

De cualquier forma este aprovechamiento económico de los recursos auríferos traería consigo alteraciones notables en el ritmo de vida de las poblaciones indígenas que habitaban esta región del concejo de Allande; y ello a pesar de que la administración romana respetaría y potenciaría a un mismo tiempo el tipo de habitat tradicional como consecuencia de que tales recintos poblacionales no sólo no iban a impedir el desarrollo y alcance de sus objetivos económicos ( $y$ en última instancia político-administrativos) sino que contribuirian, como lugares de acogida de la mano de obra, a la puesta en funcionamiento y explotación de los diferentes centros mineros.

El aspecto demográfico constituye posiblemente el problema más controvertido de cuantos corresponden a nuestro análisis al hallarse vinculado

98 Desde la perspectiva más optimista esta cifra tal vez debería ser duplicada al menos. 
necesariamente con la fuerza de trabajo utilizada en las tareas y actividades mineras: dejando de lado la cuestión de si esta mano de obra estaría configurada básicamente por elementos libres o esclavos, cuestión de la que nos hemos ocupado más a fondo en otros trabajos anteriores ${ }^{99}$, la densidad de población, al menos en los momentos de aprovechamiento más intensivo de tales recursos auríferos, debió ser abundante, pudiéndose cifrar entonces en más de un millar los habitantes de la región que estamos analiazando durante los siglos del Alto Imperio; y ello a pesar de que las imprecisiones y generalidades que nos ofrece la documentación literaria, referida al censo de las personas tributarias de todo el cuadrante nordoccidental de la Península Ibérica (Plinio el Viejo, Historia Natural 3.3.27-28), no nos permiten concretar nada más a este respecto.

Parece evidente, a pesar de todo, que esta vía de comunicación de tiempos romanos perderia gradualmente vigencia a medida que tales aprovechamientos mineros se iban debilitando y acentuándose el descenso de las tareas llevadas a cabo en los mismos, de manera que a partir de las décadas finales del siglo ॥ atravesaria por un proceso de cierto abandono, del que tardaría bastante tiempo en recuperarse ${ }^{100}$.

99 Ver, por ejemplo, entre otros, N. SANTOS, "La mano de obra en las minas romanas del Occidente de Asturias", MHA 13-14 (1992-1993) 171ss.; "Los indigenas y la minería romana del oro en el Suroccidente de Asturias", MHA 18 (1997) 219ss.; «Ejército romano y minería del oro en el Norte de la Peninsula lbérica". Hispania Antiqua 21 (1997) 93ss.; y "L.os damnati ad metalla en las minas romanas del Norte de la Peninsula lbérica". Astorica 16 (1997) 89ss.

100 Posiblemente hasta la época medieval, y quizás en conexión con las Peregrinaciones a Santiago de Compostela, no volveria a tomar de nuevo un cierto auge y actividad, que en ningún caso serian comparables a los que había adquirido en tiempos altoimperiales romanos. 
MAPA .- Vía de Pola de Altande a Grandos de Solime (via romona del Puerto del Palo)

\section{ine}
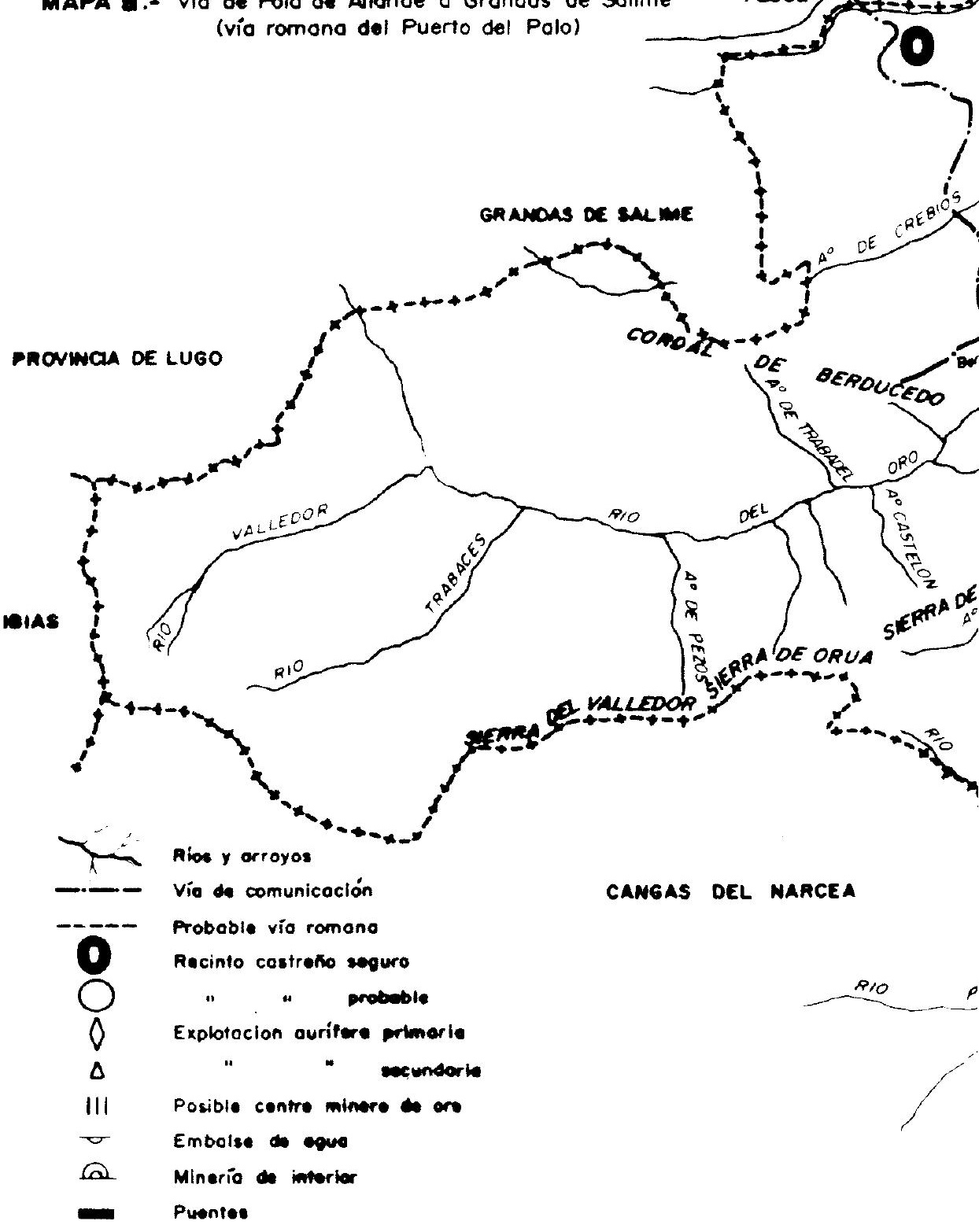


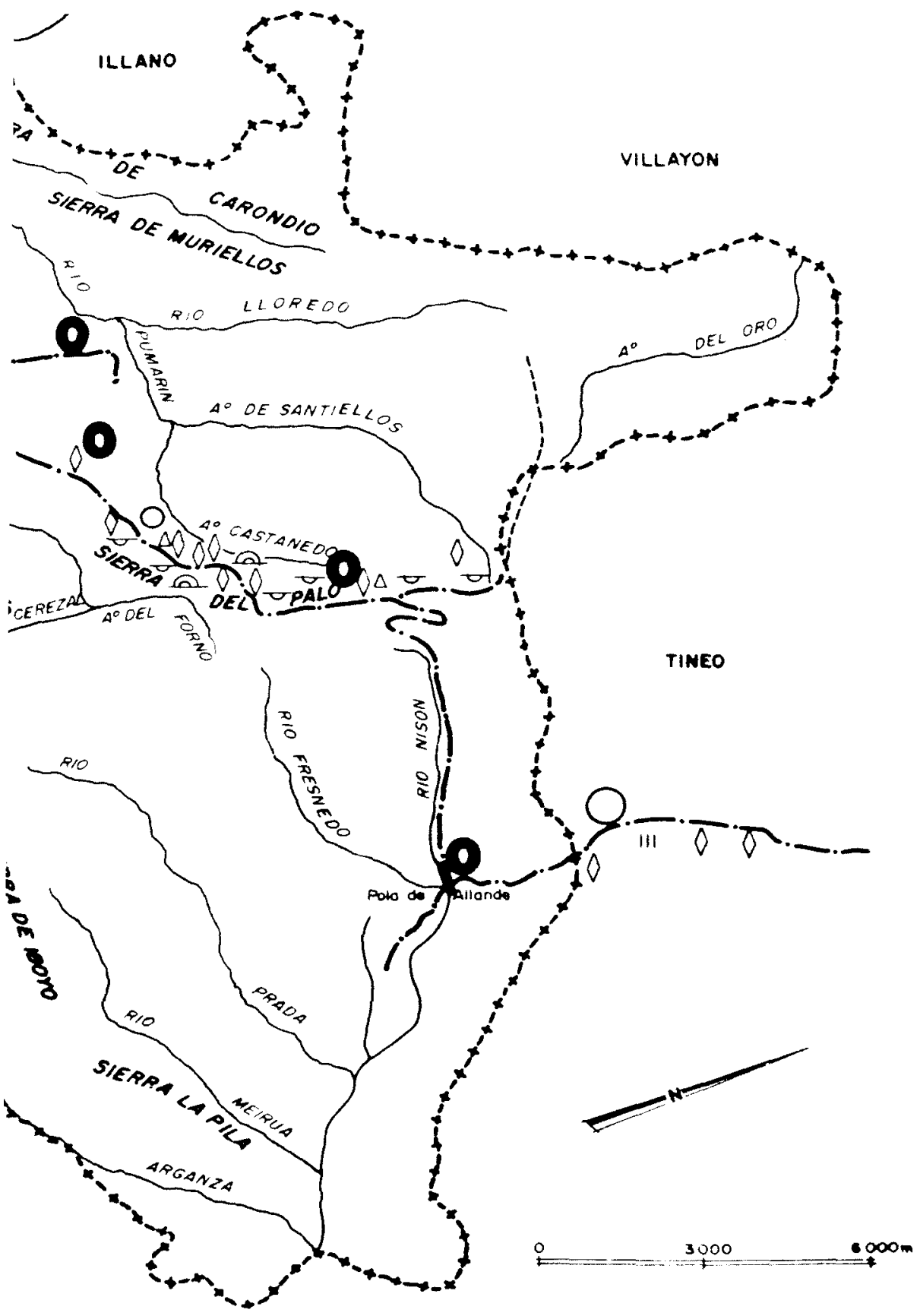

